\title{
Partidos y programas políticos. Las elecciones de 1899 en Andalucía
}

\author{
JOSE ANTONIO JIMENEZ LOPEZ
}

\section{EL DESPERTAR DE UN SUEÑO IMPERIALISTA}

En 1898 Andalucía conocerá también la confrontación y la humillación. Ello no es algo excepcional al resto de las demás regiones españolas, toda vez que, si a nivel internacional la crisis del 98 se incardina en el gran capítulo de los acontecimientos internacionales (el profesor J.PABON afirma: :Un 98 en la serie de los 98, el único no aceptado.), sin embargo posee un peculiar matiz, pues lo que para los españoles en general fue una derrota humillante o inesperada, para la historia posterior de España, fue sólo el primer eslabón de la subversión internacional.

En efecto, la magnitud de la catástrofe fue tal que resultó menor que el estupor de lo inesperado para el pueblo, y aunque la culpabilidad se le atribuye a la prensa, sin embargo fue del Gobierno y de la población en general, pues en días anteriores no existió español o andaluz, ni periódico político alguno, que se substrajera a la embriaguez bélica y desconfiase de una victoria certera ${ }^{1}$. Pero la gravedad y las consecuencias del trauma de la derrota dependió de la resistencia y del grado de salud convivencial del organismo social que lo recibe, y que en general en Andalucía,como en el resto de españa era deplorable.Para bien o para mal el pueblo español es harto impresionable y de la ciega exaltación cayó en un abatimiento que le permitía al Gobierno lanzar los cables que estimase oportunos a la cancillería de Washington en la seguridad de que todos experimentarían una sensación de alivio con el cese de la costosa e inútil sangría •².

La destrucción política de la imagen de España como gran potencia generó en el pueblo andaluz la certidumbre de un desastre moral, acabando así con la confianza en el sistema político, ya minado por la depresión económica y por la confusión ideológica. La pasividad de los

(1) El, Defensor de Granada, julio a diciembre de 1898.

(2) FERNANDEZ ALMAGRO, M. Historia política de la España Contemporánea. Madrid 1968, III, Pg. 176. 
políticos y de la sociedad en general fue la situación dominante en la península; los grandes ideales, los valores sociales y los principios políticos absolutos no despertaban ya interés a la población andaluza, de ahí el bajo número de sindicaciones que existió por estos años ${ }^{3}$. Joaquín Costa, por el contrario esbozaría a nivel nacional esta situación electoral como * una expresión o un resultante del estado político en España..., menos de medio millón de ciudadanos afiliados en los diversos partidos;lo demás era una masa neutra...x. Se trataba en definitiva de una sociedad sin pulso político alguno.

Estupor, somnolencia e ira fueron los tres estados de conciencia claramente manifiestos en el pueblo andaluz, desde el día de la derrota hasta las manifestaciones sociales en contra del pago de tributos, como la acaecida en Granada en mayo de 1899 tras una turbulenta sesión de la Corporación Municipalí. Bueno sería decir que, en la mañana del día 5 de julio Andalucía y casi toda España entera mostró sorpresa ante la noticia y ni siquiera para indignarse, tuvo ánimo el pueblo. "Desde diversos puntos -decía $\mathrm{El} \mathrm{Correo-se} \mathrm{hacen} \mathrm{desesperados} \mathrm{esfuerzos,} \mathrm{como} \mathrm{puede}$ advertirse por la lectura de la prensa,para excitar la opinión y producir alteraciones en el orden públicon.

La confusión de la derrota perturbó, incluso en aquellos días, a las mentes más serenas. Políticos como Sánchez de Toca, Azcárate, Silvela,Gamazo y Nocedal caen abatidos por el peso de la contradicción y periódicos como El Imparcial, La Epoca, El Heraldo de Madrid, El Liberal, El Defensor de Granada etc. expresan a los pocos días el clima de abatimiento de la opinión pública española y el último en concreto de la granadina. Pero a esta situación sucedió un estado de somnolencia, como bien se manifiesta en el artículo de Silvela publicado en El Tiempo, en su edición del día 16 de agosto y que titula «sin pulso* y que bien podía aplicarse también al pueblo andaluz. Decía:

-Engañados gravemente vivirán los que crean que por no vocear los republicanos en las ciudades, ni alzarse los carlistas en la montaña, ni cuajar los intereses de tales o cuales Jefes en los cuarteles, ni cuidarse el país de que la imprenta calle, o las elecciones se mistifiquen, o los Ayuntamientos exploten sin ruido las Concejalías y los Gobernadores los juegos y los servicios, está asegurado el orden y es inconmovible el Trono y nada hay que temer ya de los males que a otras generaciones afligieran. Si

(3) CALERO,A.M. El movimiento obrero en Andalucía. En Aproximación a la bistoria de Andalucía. Barcelona 1979, pg.285 ss. PALACIOS, L. Sociedad y economía andaluza en el siglo XIX. Córdoba 1977. TUSELL, J. Oligarquía y caciquismo en Andalucia.189a1923. Barcelona 1976.

(4) El Defensor de Granada de 17 y 18 de mayo de 1899. 
pronto no se cambia radicalmente de rumbo, el riesgo es infinitamente mayor, por lo mismo que es más hondo y de remedio imposible, si se acude tarde; el riesgo es el total quebranto de los vínculos nacionales y de la conciencia y de la condenación por nosotros mismos de nuestro destino como pueblo europeo; y tras de la propia condenación, claro es que no se hará esperar quien en su provecho y en nuestro daño lo ejecuta..

En el artículo se manifiesta un verdadero estado de opinión, pues no se puede dudar de que al día siguiente de la derrota, entre los andaluces subsistiera un espíritu revolucionario más o menos amplio y más o menos duradero. En efecto, el período de ira no se hizo esperar. Una campaña periodística iniciada por El Nacional y La Reforma en contra de la política gubernamental fue secundada por diarios y semanarios andaluces; igualmente se propagó un ciclo de denuncias individuales y se constituyeron tribunales de honor; también se generó un movimiento huelguístico de los trabajadores cada vez más intenso en términos tanto absolutos como relativos (de todas las huelgas conocidas sólo el $11 \%$ fueron agrarias cuando en este sector se empleaban el $70 \%$ de los trabajadores). A nivel nacional, se efectuó la expulsión del ejército de algunos generales o la amonestación y el procesamiento de otros por el Consejo Supremo de Guerra y Marina. En la alta Cámara se denunciaron, en voto particular por el senador ministerial Conde de las Almenas, las actuaciones coloniales promovidas por el Gobierno que sería secundado por una gran mayoría de representantes, y entre las clases neutras de la población se generaría su decidido apoyo a los movimiento de protestas (Ligas de Productores organizada por Joaquín Costa en Barbastro) y motines populares ( Cámaras de Comercio y Juntas en la Asamblea de Zaragoza etc.) que se difundieron con prontitud por gran parte de la península,con la anuencia ahora de los principales dirigentes políticos ${ }^{5}$.

Sin duda el pesimismo del pueblo andaluz provocado por la derrota resultaba tan extremoso como el optimismo insensato generalizado en vísperas del enfrentamiento bélico con los Estados Unidos. Pero el reverso de esa actitud implicaba también un mea culpa nacional, y ponía en entredicho cuanto había de ficticio en el sistema político canovista: el repudio de la "España vigente, denominador común del grupo de escritores de la generación del 98, no era sino una afirmación de la :España posible ${ }^{6}$. El inconformismo y la inquietud envolvía una esperanza: la apelación a la *Andalucía real•, oculta y oprimida bajo los velos de la

(5) TUÑON, M. La España del siglo XIX. Barcelona 1974,pg.377 ss.

(6) ABELLAN, J.L. La crisis de fin de siglo. Ideologia y Literatura. Barcelona 1975. UBIETO, A.,REGLA, J., JOVER, J. M. y SECO, C. Introducción a la Historia de España. Barcelona 1964, pg. 723 y ss. 
política oficial. Y de tal modo había de pesar esa dicotomía que todavía subsistía, en la trayectoria política del primer tercio de nuestro siglo, el empeño por identificar las dos andalucías. Porque en la clave política de convertir la ficción en realidad (dar cauce a las nuevas formaciones políticas al margen del sistema de turno,y atender y asimilar los objetivos minimalistas de los incipientes partidos obreros), estaba la solución de los problemas de fondo: la cuestión social andaluza.

La Andalucía de 1899 se vería surcada de heridas(una economía tradicional y anacrónica, una hacienda exhausta y una sociedad abatida que le hace incapaz de protestar por la situación). Nuestra región seguía siendo básicamente agrícola y su comercio exterior lo constituían materias primas de entre las que una tercera parte son minerales y el resto productos agropecuarios ${ }^{7}$. A nivel nacional la Hacienda se encontraba agotada, pues la deuda pública contraída para hacer frente a los déficits presupuestarios habían alcanzado cotas muy elevadas, por lo que era necesario proponer economías thasta la crueldad. (es la propuesta de Antonio Cánovas ya en 1885). La crisis económica,iniciada en los últimos años del siglo, a la par que surge el problema ultramarino, hizo añicos la apariencia de concordia social. El anarquismo ideológico volvía a ganar adeptos y en la corriente de violencia ciega, que caracterizaba los años finales, se lanza al desafío del orden social.

Por ello el siglo XIX terminaba para Andalucía y en general para España envuelto en una melancólica luz de crepúsculo. El regeneracionismo representaría la voluntad de superación para el pueblo, y la fórmula de los que, disconformes al sistema o a la marcha política que condujo al desastre, podían considerarse al margen de los errores que los posibilitaron. De aquí, que el horizonte quedase abierto sólo para los grandes disidentes, que cifraron su programa en una apelación a la autenticidad. El propio Joaquín Costa, hablando de una política quirúrgica, comentó que se había .echado doble llave al sepulcro del Cid»; en igual sentido se expresó el Presidente de las Cortes de 1899 (Alejandro Pidal) cuando en la sesión de apertura presentó el famoso discurso del ssacrificio.

\section{LA INESTABUIDAD GUBERNAMENTAL: EL GOBIERNO DE COLABORACION DE SIIVELA}

Era evidente que la permanencia en el poder del gobierno de Sagasta,aún modificado por la entrada del General Weyler,se hacía imposible. Tanto en las Cortes como en la calle ninguno de sus nuevos

(7) PALACIOS, L. op. cit. pg. 135 y ss. Periódico El Defensor de Granada del 4 de febrero de 1899. 
proyectos hubieran logrado distraer la atención por el obsesivo objetivo de reproducir el debate sobre las responsabilidades políticas de la situación postbélica, para de esta forma dejar a salvo la dignidad nacional y la sensibilidad civil. Las proposiciones presentadas a la Cámara fueron varias y los debates duraderos, más todo ello no era sino indicativo de que el Gobierno de Sagasta habían perdido también la confianza de un amplio sector de la mayoría liberal, como momentos después se puso de manifiesto con la disidencia gamacista. Sin embargo la oportunidad apetecida por la oposición surgiría en el Senado, en la sesión del día 28 de febrero en que se puso de manifiesto este clima de rechazo, y es que en dicha sesión se pondría a discusión el voto particular de Sánchez de Toca referido al proyecto de Ley sobre la cesión de Filipinas ${ }^{8}$.

En efecto, la expectación era grande y subsistía una ansiedad política excepcional; la palabra crisis estaba en todos los labios y se comentaba que el partido liberal, gastado y maltrecho por la pérdida colonial, tenía que ceder el puesto al conservador, a pesar de que tampoco este partido se considerase un eficaz instrumento de poder, pues se mostraba poco compacto. Sin embargo llegado el momento de la votación fue desechado el citado proyecto de ley de Sánchez de Toca por 120 votos en contra frente a 118 a favor, por lo que el Gobierno liberal había salido triunfante numéricamente, pero no asî moral y políticamente. Tras un breve Consejo de Ministros Sagasta planteó la crisis a la Corona, la cual procedió a llamar a consultas a los presidentes de las dos Cámaras (Marqués de la Vega de Ármijo por el Congreso y Montero Ríos por el Senado) que le manifestaron la conveniencia política de la continuación en el poder del partido liberal..Una disidencia -dijeron- no debe ser obstáculo para que el Sr. Sagasta y su partido hayan de abandonar el Gobierno... El país quiere una política liberal. Apremian mucho las cuestiones económicas y conviene elegir para el Gobierno a los que con menos dificultades y en menos tiempo puedan convocar elecciones"?

Silvela, por su parte,manifestaba que no era tiempo de dar soluciones transitorias o provisionales,y puesto que el partido liberal carecía de programa, reclamaba el poder para la Unión conservadora que tiene la solución que reclamaba la opinión pública para las cuestiones económicas, financieras,administrativas y políticas. El partido de Unión conservadora -dice-sostiene la necesidad de un cambio de política que represente una sanción de las responsabilidades contraídas por el Gobierno liberal. Sin embargo a este intento de la Unión se opondrían resueltamente el Duque de Tetuan y Romero Robledo que manifestó: •Que la solución de

(8) FERNANDEZ ALMAGRO,M. op. cit. pg. 213 y ss.

(9) El Imparcial, del 2-3-1899 
la crisis es una cuestión de suma sencillamente. Ver y saber qué solución reúne mayor número de elementos y más fuerzas en la opinión pública. Es indudable que la Unión conservadora sumaría las fuerzas del General Polavieja y nada más...En cambio el partido liberal contaría con el concurso de los partidarios del General Weyler, de los del Sr. Canalejas, de los que yo represento y de los importantísimos y difíciles de determinar simpatizantes republicanos ${ }^{10}$.

Así la situación, y tras porfiados requerimientos a Sagasta de la continuidad en el Gobierno del partido liberal por medio de un Gabinete presidido por el Marqués de la Vega de Armijo o por Montero Ríos ${ }^{11}$, ello no fue posible, por lo cual el día 3 de marzo sería llamado a Palacio Francisco Silvela para encargarle la formación del nuevo Gobierno, que prestaría juramento en la mañana del día 4 , quedando constituido por:

- Presidencia y Cartera de Estado: Francisco Silvela

- Gracia y Justicia: Manuel Duran y Bas

- Gobernación: Eduardo Dato

- Hacienda: Raimundo Fernández-Villaverde

- Fomento: Marqués de Pidal

- Guerra: General Polavieja

- Marina: General Gómez Imaz

Era en realidad un ensayo de alianzas de fuerzas diversas para así asegurar la colaboración de dos valiosos líceres políticos, Manuel Duran y Bas y el General Polavieja. Sin embargo, las opiniones vertidas en la prensa andaluza sobre este Gobierno no eran más que ecos o redundancias de los juicios que días antes se habían esgrimido sobre el programa de Unión conservadora propuesto por Silvela.

Uno de los estímulos que prevaleció en la actuación del Gobierno fue la superación de cuantos obstáculos ("por revolucionarios") se oponían a la obra de reformas radicales que tenían programadas ante la situación verdaderamente catastrófica de la economía (déficit presupuestario,caída de la peseta,inflación etc.). Intentaron contenerla reduciendo los límites de emisión del Banco de España, fijando nuevos impuestos en la Ley de Presupuestos de $1899-1900$ y con una política de austeridad del Gobierno (redujo considerablemente los gastos de los Ministerios de Guerra, Marina y del Consejo de Estado, suprimió las cesantías de los ministros, reajustó los gastos de representación y dietas en las Diputaciones Provinciales, así como los destinados a la dotación

(10) El Imparcial, del 23-2 1898.

(11) La Epoca, del 11-1-1899. 
del culto y clero). Este modo de proceder mostraba una evidente coherencia ética con el proyecto político presentado a la opinión pública ${ }^{12}$. Pocos días después, el 16 de marzo, la Reina Regente firmaría el Decreto de disolución de las Cortes, convocando nuevas elecciones generales para el próximo día 16 de abril.

\section{PARTIDOS POLITICOS EN ANDALUCIA EN 1899}

La crisis de 1898 constituye una crisis finisecular que conlleva, a parte del desatre colonial,el hundimiento de la conciencia nacional, la disolución por falta de credibilidad popular al sistema político de la Restauración, y el inicio de la inestabilidad gubernativa y convivencial en la España del siglo XIX. Esta situación, extrapolable también a nuestra región; se genera por dos impulsos distintos: de una parte porque el turno pacífico en el poder (el bipartidismo subsistente) se efectúa mediante una elecciones fraudulentas que no representan, en la mayoría de los casos, la opinión real de los electores; y de otra la propia incapacidad de los equipos de gobierno y autoridades políticas locales constituidas que reflejan una profunda crisis interna de escisión y conformación de minorías ideológicas. Se trata de un momento crítico, de una descomposición ideológica inevitable.

En cuanto al partido conservador,ya en 1891 se presentaba como una organización política convertida en un mecanismo de disfrute entre los miembros del presupuesto público. La incapacidad para establecer una mejor gestión económica y la existencia de tensiones internas, son los móviles principales que le han llevado a esta situación. En efecto, los desacuerdos personales entre Silvela y Romero Robledo en relación al control del sistema electoral (más cualificado éste último en hacer sus eleccciones), determinó que Cánovas se inclinase por Romero Robledo, lo que motivó la salida del primero de las filas del conservadurismo.

Respecto al partido liberal fusionista también se vio afectado por una evidente crisis ideológica interna, producto del enfrentamiento entre el republicanismo de unos y la lealtad monárquica de otros, del proteccionismo de los gamacistas y del librecambismo de los seguidores de Segismundo Moret, o del autonomismo en ultramar de los primeros y del sometimiento de los segundos; a ello hemos de sumar el agotamiento programático. En efecto, al partido le tocó dilucidar el momento más brillante y difícil de la historia de España: el saneamiento de la economía y la liquidación del imperio ultramarino. Sobre estas cuestiones se suscitaron posturas muy enconadas entre sus militantes. En cuanto a la políti-

(12) FERNANDEZ ALMAGRO, M. op. cit. pg. 219 y ss. 
ca económica (.presupuesto por la paz") gestionada por Gamazo en el Ministerio de Hacienda, no pudo llevarse a buen fin por causa de la guerra de Melilla de 1893 y que llevó al partido liberal a no ser capaz de superar el obstáculo, ni ofrecer otras alternativas. Respecto a la cuestión de ultramar, desde el Ministerio otro gamacista(Antonio Maura) afronta la cuestión dándole una orientación autonomista, a lo que se oponen los conservadores y amplios sectores del liberalismo fusionista movidos por intereses económicos personales que tenían en estas tierras, y que acabaron por abandonar al Gobierno de Sagasta y al propio partido.

La situación de los partidos era de incertidumbre, de discordia y en definitiva de crisis interna, pues el desastre colonial les había distanciado de las fuerzas vivas del país (el pueblo) y vanamente pretendían atraer a las clases neutras. Fueron muy frecuentes los anatemas y elocuentes ironías ("gremios de oligarcas", "planas mayores sin soldados", "bolsas de contratación del poder. etc.) propaladas contra los partidos en la prensa local ${ }^{13}$. Las actuaciones de Silvela, Pidal, Sánchez de Toca, Azcárate y otros muchos prohombres políticos confirman este estado de opinión.

Era claro que la tragedia nacional de Santiago de Cuba y de Cavite perturbó la cohesión ideológica que hasta entonces presentaban los bloques políticos. En efecto, si el desastre colonial afectó más profundamente al partido liberal fusionișta que desde el Gobierno tuvo que hacer frente a la situación,el drama de Sta. Agueda en agosto de 1898 perturbaría también al partido conservador. Por ello, si hasta 1898 los bloques ideológicos aún se presentaban homogéneos y compactos, tras estos acontecimientos se rompería el Pacto del Pardo de 1885 y la dinámica del poder se tornó inestable, pues en cada bloque se puso de manifiesto el carácter sumativo de heterogéneos grupos ideológicos estratificados incoherentemente y que generarian disensiones internas. Pocas veces se ha registrado en la historia ideológica española del siglo XIX tantas agrupaciones, camarillas y parroquias como en 1899.

En efecto, del bloque conservador surgirían los silvelistas, los neocatólicos de Pidal, los inquietos shúsares" de Romero Robledo y los melancólicos caballeros del "Santo Sepulcro. del duque de Tetuan; de parte del núcleo liberal resurgirían los "cimbrios", los "fosforitos", los -radicales", los "gamacistas" que difundían sus principios programáticos por medio del periódico $E l$ Español, y el reducido grupo en torno a Canalejas, con el Heraldo de Madrid como medio de difusión, y que si bien no constituyeron una disidencia propiamente dicha, si al menos una actitud de disconformidad expectante a las directrices adoptadas por el bloque liberal. Los demás grupos políticos se verían también impregna-

(13) El Defensor de Granada, del 22-3-1899. 
dos del ambiente desconcertado; a tal efecto, en el bloque republicano cundieron las desavenencias y cada líder (Castelar, Salmerón, Pi y Margall etc) utilizaría un lenguaje caduco e incomprensible; sólo de vez en cuando las actuaciones de Blasco Ibañez, Soriano y Lerroux en provincias hacen despertar al republicanismo del letargo de las postrimerías; en cuanto a la entente cordiale de carlistas e integristas, con sus órganos de difusión El Correo Español y El Siglo Futuro respectivamente, quedaría también tocada de muerte, pues se recrudecieron entre ellos la vieja polémica programática (•Manifiesto de Lóredan* por gubernamental y la voz prorevolucionaria de Mella) ${ }^{14}$.

Así todos los partidos por su imprevisión o desidia se vieron atemperados y divididos,ninguno había arraigado fuerte en là conciencia andaluza; cuando aconteció la catástrofe colonial todos, cual más o cual menos, hicieron dejación de sus principios programáticos y por el contrario pugnó porque anidara en cada español o andaluz una conciencia revolucionaria ( Silvela cuando escribió su artículo "La España sin pulso", Pidal cuando el discurso en los Jardines, Gamazo cuando el mitin de Santander, Maura cuando el banquete de Sevilla, Sánchez de Toca cuando la fiesta inaugural de la Academia de Jurisprudencia, Salmerón cuando dijo: :Los mejores servidores de la Patria serán los que ciñendo espada arrollen los obstáculos que se oponen a su engendramienton, Mella cuando anunciaba catástrofes apocalípticas, el Duque de Tetuan cuando se negaba a ser Ministro de un país anárquico, Moret cuando su conferencia en el Círculo Mercantil...etc.) ningún partido supo aprovechar o canalizar para hacerle salir del estado de postración en que estaba sumido.Sólo:las clases productoras asumirán la situación y se enfrentarán fieramente a los ineficaces políticos con la pretensión de la reconstrucción y europeización del país. La Liga de Contribuyentes de Ribagorza envió una circular, redactada por Joaquín Costa, a los agricultores y ganaderos para la organización de la Cámara Agrícola del Alto Aragón, y cuyo ejemplo iba a ser seguido por los industriales y mercantiles, que sumados al movimiento agrario constituirían la "Liga Nacional de Productores.'15.

- Ya que en la vida nacional -decía el Documento de la Cámara de Comercio de Cartagena- no representamos a los que legislan y gobiernan, sino a los que trabajan y producen para mantener a los demás, deber nuestro es, sin invadir funciones que no nos competen, señalar, por lo menos de un modo autorizado y concluyente, a nuestros gober-

(14) MARTINEZ CUADRADO, M. Elecciones y partidos politicos en España, 1868-1931.Madrid 1969, pg. 147 ss. El Defensor de Granada en sus ediciones de los días 9, 19 y 22 de marzo de 1899.

(15) TUÑON, M. op. cit. pg. 338 y ss. 
nantes y legisladores donde están las fuentes de nuestras desdichas para que se cieguen...; que no es desde las alturas del Poder en donde las mezquinas tendencias de un partido ocupan más al prócer que la gobernación de la Patria, ni desde la poltrona de los altos empleados... desde donde se distinguen los males públicos ${ }^{16}$.

\section{POSTULADOS TEORICOS DE SUS PROGRAMAS}

¿Qué presentaban los partidos como alternativa?. Nada, pues el partido liberal, esclavo del desastre en el Gobierno, ofrecía al país en una mano la humillación del Tratado de París y en la otra la célebre carta de disidencia de Gamazo. Por su parte, el partido conservador, huérfano en la jefatura, mostraba una aparente reunificación interna, tras el abrazo de Silvela y Pidal en el ruidoso banquete de los Jardines del Buen Retiro.

\subsection{El Intento renovador de la Unión Conservadora}

En el Manifiesto del General Polavieja ${ }^{17}$,se esbozaba un programa ideológico realista, sin grandes pretensiones políticas.Es quizá el primer ensayo de regeneración que desde el neoconservadurismo tomó forma política. La repentina popularidad del General y sus ataques continuos a los políticos civiles que sustituían sla reforma práctica por la política de abstracción ${ }^{18}$ le convirtió en el candidato ideal para la burguesía. Los principales campos sobre los que centraba las prioridades de actuación política fueron:

- Saneamiento de la Hacienda Pública. Se hacía necesario exigir sacrificios al país para restablecer el crédito y el arreglo definitivo de la Deuda. Centraba su atención en los impuestos, especialmente los indirectos que habían de sufrir ligeros aumentos; «Nosotros hemos admitido y aceptamos -dice el General- que los sacrificios de esa riqueza sean iguales a los demás sacrificios que sufre y padece la riqueza territorial, que sufren la riqueza industrial y mercantil y hemos aceptado que tributen así también como los demás valores mobiliarios... Nosotros entendemos que no es posible prometer al país la rebaja de impuestos, y que si algunos, especialmente los indirectos, habrán de sufrir nuevos aumentos..., exceptuando siempre de todo recargo la contribución de inmuebles, cultivo y ganadería...; en demanda de restricciones económicas a las grandes economías para poder establecer una implacable disminución de gastos y

(16) El Diario de Murcia del 3-1- 1899

(17) El Imparcial en su edición de 8 de enero de 1899.

(18) CARR, R. España 1808-1939. Barcelona 1968, pg. 457 y ss. 
una reducción salarial para aquellos otros estamentos sociales que perciben gratificaciones o sueldos extraordinarios. Se propone que para llevar a la realización esta plan se diera entrada a las representaciones colectivas ya sean municipales, ya provinciales, ya gremiales, con el fin, no para concertar con ellas los cupos de manera irrevocable y permanente, sino para que aportaran datos de la situación real y poder contribuir así a una mejor adecuación del programa en beneficio de la actividad regional, provincial o municipal, y en definitiva al conjunto de la obra nacional.

- Reorganización judicial, tratando de reprimir los abusos y escándalos de los jurados. Por ello propone la separación más completa entre política y administración de justicia, empleando como una base eficaz la .escala cerrada. para la carrera en la Administración de justicia.

- Respecto a la Guerra y la Marina proponía una atención prioritaria a la defensa de costas y fronteras,ante todo por razón de situación estratégica de la península,así como a la reposición de nuestra vetústa escuadra y armamento.

- Reorganización y creación de actividades mercantiles y agrarias. Se propone desarrollar los servicios del Ministerio de Fomento, otorgándoles un carácter más técnico, ajenos a cualquier intervención política o vaivenes de los partidos, y orientarlos a que se afanen por la regeneración de la idiosincrasia del pueblo español y de su desenvolvimiento material.

- Reformas en la administración local, municipal y provincial descentralizándola de la propia administración central, a tal suerte que el sean los Gobernadores Civiles los únicos representantes verdaderos del Poder Central, rompiendo así todos los demás lazos que han generados corruptelas lamentables que protegen a determinados intereses.

¿Pero como se aceptó esta declaración programática por los miembros de la Unión Conservadora?.El General Martínez Campos la asumió en su casi totalidad, aunque destacó con énfasis el peligro de la formulación regionalista que en el programa se desvela y la excesiva autonomía que concedía a los antiguos reinos. Romero Robledo condenó también los anuncios regionalistas expresados. "Aumenta la conveniencia de hacer cuanto antes -dice- de hacer una concentración conservadora. El programa impuesto por el General Polavieja y aceptado por Silvela, sostiene dos principios que son una amenaza tremenda para cuanto es vida y sustancia del régimen democrático...El primer principio es el regionalista..., que hiere la unidad del país, la constitución del ejército y el ser económico de la Nación.El segundo es el ultramontano, pues en un país donde la libertad amparaba el respeto a todas las creencias y confesiones, se viene en él a plantear la cuestión religiosa con la que se despertaría pasiones ya extinguidas y se dificultaría la aún más convivencia en una época que más se 
necesita del reposo y de la paz para fomentar las fuentes de riqueza y hacer frente a las inmensas obligaciones del Tesoro. ${ }^{19}$. El General Weyler manifestó su disconformidad al principio regionalista y propone la fundación de un gran partido liberal en el que se incorporasen incluso aquellos republicanos que, defensores del patriotismo y de las ideas democráticas, quisieran contribuir a la regeneración del país.

Desde otro ámbito ideológico Canalejas, en una de sus crónicas políticas publicada en la Nouvelle Revue Internacionale, expresó su opinión de que: "Lo que más me entristece de esto proyecto es la complicidad de ciertos elementos conservadores que manifiestan tendencias regionalistas. Es una innovación temeraria y atrevida, y no sólo poco conservadora, sino revolucionaria...Esta reacción, favorecida por los regionalistas, dislocaría completamente la patria, y de esta dislocación serían responsables los conservadores si continuasen locamente por el camino de la perdición que se han aventurado. También en su conferencia (*La crisis nacional.) pronunciada en la Asociación de la Prensa, y refiriéndose al programa de la Unión Conservadora, Canalejas expresó su oposición a los organismos de tendencia tradicional,sentando la afirmación terminante de que, siendo la reconstrucción de la Nación una obra de cooperación social, no podía ser realizada más que por instituciones democráticas.Se pronunció en favor de la descentralización del régimen local en materia de enseñanza,beneficencia y de otras materias administrativas, y cuya dejación conducirían al fomento del regionalismo y al riesgo de la negación de la Patria ${ }^{20}$.

En estas condiciones de hostilidad y recelo fue acogido el programa de la Unión Conservadora, tanto por los liberales como por los carlistas y algunos elementos disidentes del conservadurismo (Gamazo y Duque de Tetuan) que lo hallaron poco expresivo. Sólo los partidarios del catalanismo y los representantes de las clases productoras en la Cámara de Comercio le darían su apoyo. Era claro que el polaviejismo no podía subsistir como movimiento sin la alianza con el partido conservador.

Sería en la conferencia de Francisco Silvela celebrada en el Círculo Conservador de la Carrera de S. Jerónimo el día 7 de enero de $1899^{21}$ cuando se definiesen los postulados básicos del programa político del conservadurismo adicto. Se trataba de un programa renovador, donde se definían las reformas radicales, reflejo de las profundas modificaciones ideológicas del partido en los ámbitos político, social y económico. Se proponía:

(19) El liberal del 17-6-1899. SOLE VILLALONGA, G. La Reforma fiscal de Villaverde, 1899 1900. Madrid 1967.

(20) El Liberal de 8-2-1899.

(21) Periódicos El Imparcial y El Liberal en sus ediciones del 8-1-1899. SILVELA, F. Antǐculos, discursos, conferencias y cartas. Madrid 1944, III. 
- Reorganizar la Hacienda Pública con las liquidación de la deuda contraída por la guerra colonial (cerca de 300 millones) y que grababan a la economía del país; y una enérgica y severa política de nivelación que reformara las rentas públicas, creando otras nuevas con las que poder otorgar recursos ordinarios.

- Descentralización administrativa del poder central.

-Incremento de las actividades económicas industriales, mercantiles y agrícolas.

\section{-Fomento de las Obras Públicas y Comunicaciones.}

Para ello Silvela requería de sus colaboradores energía y abnegación en la entrega y sacrifico y austeridad en lo material, "con la mira puesta en el ideal -dice- ,que es lo único que han realizado las grandes empresas morales en el mundo.22. Aunque a simple vista estos principios programáticos eran coincidentes con los propugnados por la Unión Conservadora y por otros más grupos políticos, sin embargo se diferenciaban en cuanto al procedimiento y conducta que se estimaba de inaplazable necesidad.

\subsection{Postulados del partido liberal-fusionista}

En la reunión habida en el Salón de Sesiones del Senado, bajo la presidencia de Sagasta, se expusieron las líneas programáticas de actuación del partido ${ }^{23}$ :

-Reorganización de la Administración Pública, desembarazándola del inútil expedienteo,y así poder disminuir los gastos públicos; consecuentemente los afanes regionalistas, que soñaban con una insensata desmembración del Estado, serían rechazados tenazmente; por el contrario se fomentaba una prudente reforma que diera a la provincia una amplia autonomía en el ámbito de la administración ordinaria,aunque siempre salvando la unidad patria.

-Fomento de la riqueza nacional, aliviando las impuestos que recaían sobre los sectores de producción (especialmente sobre la agricultura), estableciendo una distribución equitativa de las cargas económicas y la nivelación de los presupuestos; de esta forma se consagraría el fomento de la riqueza..España puede reponerse -dice Sagasta- si huye de aventuras...No hay que hablar de reformas políticas... que dividan a los españoles, sino atender al fomento del trabajo y de la producción nacional.

-Fomento de las Obras Públicas y las Comunicaciones mediante un plan de construcción y mejora de la red de ferrocarriles secundarios, de caminos vecinales, de canales de riego y edificios públicos. También se prestaba especial atención en hacer disminuir las cuantiosas tributaciones

(22) El liberal del 1-6-1899

(23) Periódicos El Liberal y El Imparcial en sus ediciones de 11 y 12 de febrero de 1899. 
que pesaban sobre la marina mercante, incentivando así el comercio exterior español.

-Actuación en política social a través de una planificación de la instrucción pública y de una normativa social y laboral justa en relación con la clase trabajadora, pues así se podría restablecer la disciplina social y el espíritu de concordia convivencial, excluyendo cualquier peligro que dificultase el mantenimiento de un orden social estable.

-En politica de Defensa y de Administración de Justicia el partido proponía dotar al ejército y al poder judicial de los medios necesarios y adecuados para una mayor eficacia y cualificación profesional, librándoles así de toda injerencia política.

Sin embargo, cuando el Gobierno liberal de Sagasta se proponía llevar a efecto el retoque necesario del Gabinete (supresión de la cartera de Ultramar) y las reformas correpondientes a los postulados de su programa político,fue cuando se produjo la disidencia de los gamacistas, que unirían sus votos a la minoría conservadora, coadyuvando así a la caída del Gobierno.

\subsection{Postulados del partido republicano}

El sector posibilista del republicanismo, concienciado del estado de inquietud subsistente, envió a Castelar un mensaje firmado por Pérez Costales, Sol y Ortega, Calixto Rodríguez,Martín de Olías, Solier, Baselga, Ruiz Chamorro y Miguel Moya en el que le instaba a la defensa del espíritu democrático, puesto en dificultad por conjuras políticas conservadoras al amparo de satisfacciones cortesanas. Por su parte Castelar, en contestación a dicho mensaje, trazaría en un discurso público ${ }^{24}$ los principios básicos del grupo republicano. Se concretan en:

- Fomentar una política de progreso que sustituya al inmovilismo público.»A la derecha debemos decirle -afirma Castelar- que no subsistirán los poderes extraños a la sociedad si repugnan ungirse...con el óleo de la soberanía nacional,y a nuestra izquierda, que no sueñe con fórmulas redentoras por ningún pensador... que suponga una trucidación de nuestro Estado único".

- Desarrollar una política social adecuada, sin evocación absurda de clases, jerarquías o antiguos gremios, pero tampoco con la supremacía de una amplia base social trabajadora,ya que en la democracia debe subsistir la armonía de todos sus integrantes. Por ello, para alejar cualquier catástrofe social, defiende el apoyo a toda conciliación entre el capital y el trabajo, y a la propiedad individual. Así se evita toda problemática social y las incipientes chispas revolucionarias.

(24) El Liberal, de 19-2-1899 
-Actuación en materia de presupuestos.Propone el mantenimiento de un presupuesto nacional único con incorporación de los gastos de dotación del culto y clero.

- Defensa del principio de libertad. Se reconocía el derecho de libertad de imprenta, de libre expresión, de educación (aunque exista una escuela oficial) y de religión (aunque también se mantenga una Iglesia oficial).

- Política de Defensa. Defiende el servicio militar obligatorio y la no supresión del ejército permanente que es indispensable en toda Nación que desarrolle una política progresiva.

-Implantación del sufragio universal, propugnando el reconocimiento pleno en España, sin limitación alguna y sin el fomento solapado del retraimiento electoral. Así se mantendría una evolución progresiva de la democracia, sin peligro alguno de interés revolucionarios (golpes de Estado desde arriba o dictaduras proletarias respectivamente).

.Con estos propósitos -dice Castelar- se consigue adelantar...

Para entonces digo lo que sigue: oíd a un viejo a quién oían los viejos cuando era joven. Desechad toda idea de fundar una república con los republicanos y para los republicanos solos. La República es como el sol, para todos los españoles, forma suprema de la libertad y del derecho."

\subsection{Principios teóricos del grupo político gamacista}

No ofrece duda que los políticos de la sizquierda liberal. que se opusieron a las actuaciones del Gabinete de Sagasta, representaron el último esfuerzo de la clase media para escapar de la tutela de la oligarquía territorial. Uno de ellos fue Germán Gamazo que, con un grupo de seguidores, constituiría una minoría disidente que, representando a una clase media campesina defensora de una política proteccionista, acabaría concediendo el voto a los conservadores. En cuanto a las directrices de su programa político fueron definidas en un discurso que fue reproducido por el periódico El Español (26 de febrero de 1899). Estas eran:

-Desarrollo de un programa de regeneración económica justo, liquidando el pasado y preparando el porvenir con gallardía y sin hacer recaer el peso económico sobre las clases sociales más pobres a expensas de aliviar los impuestos a los poderosos..Es así -dice- como se contribuye al desarrollo de la riqueza pública.

- Desarrollo de un programa de regeneración política e institucional, estableciendo un nuevo sistema que, sin lastimar ningún derecho, cuidara de asegurar la independencia de la Nación; por ello se potenciaban a aquellos organismos públicos encargados de la seguridad y defensa del territorio, y se suprimían a aquellos otros que resultaran inadecuados por su ineficacia.

-Defensa del sufragio universal. "Secundar -dice Gamazo- la obra regeneradora, poniendo el mayor esfuerzo en afianzar lo que estimo principal entre todas las libertades: la del sufragio. 
- Amparo al derecho de libertad, bien sea de imprenta, de reunión o de asociación, siempre que se mantenga dentro de los límites constitucionales, pues de lo contrario ello concluiría en revolución y anarquía.

Hasta aquí hemos presentado todos y cada uno de los programas políticos que, los principales partidos, ofrecieron a la opinión pública andaluza en la campaña electoral del día 16 de abril. Sobre todo hemos de hacer incapié que en todos ellos se refleja la crisis ideológica en que cada partido se hallaba sumido, y el papel preponderante que ejercían sobre la región las clases productoras, ya que en cada uno de estos programas políticos se incorpora la cuestión económica y las distintas soluciónes requeridas por ellos (reorganización de los servicios). De hecho, en los manifiestos políticos de los partidos en el proceso electoral también se percibía un solo clamor: "Economías y reorganización de servirios* que había sido propalado en Barbastro en 1893 por la Asamblea de la Cámara Agrícola del Alta Aragón y consolidado después por la Liga Nacional de Productores ${ }^{25}$.

\section{ELECCIONES DE ABRIL}

Silvela quería mostrar el decidido empeño de su Gobierno en atajar los abusos y corruptelas subsistentes en la Administración pública,al igual que infundir un espíritu de pulcritud y honestidad en el proceso electoral que se avecinaba ${ }^{26}$, por ello se preocupó de proveer los cargos públicos con personas de criterio recto.Mucho celebraríamos -dice El Defensorque fueran sinceros tales propósitos, pero mayores motivos tenemos para suponer que las próximas elecciones serán una farsa más que añadir a la vergonzante historia del régimen parlamentario, y que la ley será burlada una vez más y que los muñidores y caciques de todas las categorías escamotearán la voluntad nacional, resultando en definitiva un Parlamento hechura de Silvela y sus amigos ${ }^{27}$.

Teóricamente en Andalucía como en el resto de España existía una democracia *cuasi* perfecta. Pero la extensión del voto a masas de población que carecían del mínimo de cultura necesaria para lanzarlas a potenciar sus derechos legales (a hacer efectiva su "ciudadanía") y, que por añadidura, se hallaban sujetas a una situación económica que convertía en sueño sus libertades cívicas (especialmente en los grandes dominios rurales donde el caciquismo rural convertía en provecho propio los modestos poderes y servicios municipales), hizo mucho más grave que lo había sido nunca, el distanciamiento entre la Andalucía real y la Andalu-

(25) MARTINEZ CUADRADO, M. op. cit. pg. 152 y ss. ABEL.LAN, J.L. op. cit. pg. 135 y ss.

(26) La Gaceta de Madrid del 24-3-1899

(27) El Defensor de Granada en su edición de 9 de marzo de 1899. 
cía oficial ${ }^{28}$.. Y ello -dice $E l$ Defensor-porque la desvergonzada voluntad de los caciques se ha apoderado de nuestros organismos y procedimientos políticos, y no hay otra voluntad que consultar sino la del Ministro de la Gobernación expresada en el encasillado. Tan hondo está el mal que sería preciso un cambio de costumbres radicalísimo para desarraigarlo. ${ }^{29}$. En efecto, la administación pública, la justicia provincial, los servicios y cargos políticos (desde el Alcalde y el Juzgado de Guardia, y desde el camino vecinal hasta el préstamo del pósito), todos eran instrumentos y granjería del cacicato.Consecuentemente, la ficción electoral y las posibilidades que tenía el Presidente del Consejo de Ministros, de obtener de la Corona el decreto de disolución de las Cortes, redujeron a pura fórmula la cosoberanía expresada en la universalidad del sufragio. Jamás se dio el caso que el partido dominante perdiera en Andalucía las elecciones convocadas, lo que en lugar de ser los gobiernos consecuencia de la voluntad popular reflejada en la mayoría parlamentaria, siempre fue esta mayoría obra de los Gobiernos que estaban en el poder. Era evidente que ante esta farsa electoral la indiferencia del electorado era el mal terrible, pues hacía de la política una solución sin esperanza y un juego de audacia, patrimonio exclusivo de los "peores" ciudadanos.

Sin embargo, nunca como en estas elecciones se hizo tan necesario que la población andaluza depositara su voluntad en las urnas y eligiera libremente a sus representantes,llevando a las Cámaras hombres enuevos. que rompieran con los moldes de la rutina institucional y que personificasen algo más que la voluntad del Ministro de la Gobernación y de los caciques.Los aspectos de concreción de intención de voto y de participación electoral pueden seguirse, mejor que en la suma total de votos, en el resultado de estos en las capitales de provincia; lo que en todo caso sí se evidencia es la diferencia de valor del voto ciudadano respecto del campeśno (siempre se decantó en perjuicio de este último), manifestación clara de la dualidad campo-ciudad en nuestra región y meridiano espacial de la contradicción democrática cuando se asienta sobre una realidad económico-social en subdesarrollo.

Así las cosas, todos los grupos políticos se aprestaban a la confrontación electoral; el partido liberal y los republicanos usarían de todos los medios a su alcance para difundir sus programas, pues tanto en la prensa andaluza como en los numerosos mitines celebrados, se abogaba por una participación activa de resonante proselitismo; los carlistas apelaran al retraimiento, pues su líder Barrio y Mier recibiría un telegrama cursado en

(28) El Defensor de Granada en sus ediciones del 1 y 9 de marzo y del 1 y 16 de abril. TUSELL, J. op. cit., pg. 38 y ss. BARRAGAN MORIANA, A. Caciquismo y sufragio universal: Las elecciones generales de 1891 en Córdoba. Comunicación presentada al $I I$ Cong. Hist. Andal. Córdoba 1991.

(29) El Defensor de Granada en su edición de 9 de marzo de 1899. 
Venecia así se le ordenaba (*No habrá -decía- en la futuras Cortes Diputados Carlistas, pero podrá haber Carlistas Diputados.); los grupos integristas también apelarían al retraimiento, como así se deduce de la campaña desarrollada en nuestra región por su líder Cándido Nocedal. En el corto espacio de un mes la inquietud política de los partidos se trasladó a la población andaluza, y aunque se intentaron a nivel nacional de reiteradas coaliciones electorales (la iniciativa de Romero Robledo de organizar un amplio bloque electoral donde tuvieran cabida toda la izquierda monárquica no prosperó; tampoco los intentos de una unificación republicana), las elecciones se celebrarian sin alianza alguna, concurriendo independientemente cada partido ante el electorado andaluz con el atractivo de su ideario programático a la solución de los problemas subsistentes.

Triunfaron en Andalucía los conservadores-adictos con un total de escaños de 43, siguiéndole los liberales-fusionistas con 17 , los gamacistas con 4 , tetuanistas con 2 , romeristas con 2 y republicanos con 1 escaño. Resultaron elegidos por:

\section{Diputados}

José Cárdenas Uriarte

Juan Cassinello y Cassinello

Segundo Cuesta Haro

Juan José Jiménez Ramírez

Francisco Jover Tovar

Emilio Pérez Ibáñez

Antonio Soler y Márquez

\section{Provincia de Almeria}

Localidad

Almería

Almería

Purchena

Vera

Berja

Almería

Sorbas

\section{Partido}

Conservador-adicto

Liberal-fusionista

Conservador-adicto

Conservador-adicto

Conservador-adicto

Conservador-adicto

Conservador-adicto

\section{Provincia de Granada ${ }^{30}$}

Alberto Aguilera y Velasco
Conde de Agrela
Conde de Benalúa
Conde de Castillejo
Duque de Baena
José España y Lledó
Cándido Hernández Velasco
Rafael Jiménez de la Serna
Antonio Marín de la Bárcena
Marqués de Portago
Bruno Portillo y Portillo

Albuñol
Granada
Granada
Loja
Baza
Orgiva
Motril
Alhama
Guadix
Granada
Granada

Liberal-fusionista

Conservador-adicto

Tetuanista

Conservador-adicto

Conservador-adicto

Conservador-adicto

Conservador-adicto

Conservador-adicto

Gamacista

Conservador-adicto

Conservador-adicto

(30) El Defensor de Granada del día 19 de abril publicó los resultados definitivos de las elecciones en la provincia. La cuantificación de votos obtenidos por cada una de los candidato fue: Alberto Aguilera y Velasco, 6.520 votos; Conde de Agrela, 9.290; Conde de Benalúa, '.607; Conde de Castillejo, 9.645; Duque de Baena, 9.645; José España y Lledó, 5.094; Cándido Hernández Velasco, 3.152; Rafael Jiménez de Laserna, 5.281; Antonio Marín de la Bárcena, 4.674; Marqués de Portago, 7.432; y Bruno Portillo y Portillo, 9.663. 
Provincia de Jaén

José de Bonilla y Forcada

Miguel M. Gómez y Sigura

Torcuato Luca de Tena

Juan Montilla y Adan

José del Prado y Palacio

Marqués de la Rambla

Vizconde de Irueste

Vizconde de Irueste

Pablo G. de Zúñíga y López
Jaén

Cazorla

Martos

Jaén

Jaén

Ubeda

Baeza

Ia Carolina

Villacarrillo
Conservador-adicto

Liberal-fusionista

Liberal-fusionista

Liberal-fusionista

Conservador-adicto

Conservador-adicto

Conservador-adicto

Conservador-adicto

Conservador-adicto

Provincia de Córdoba

Antonio Barroso y Castillo
Luis Gamero-Cívico Benjumea
Jerónimo Palma Reyes
Antonio Quintana Alcalá
Esteban Ruiz-Montilla Ramos
José Sánchez Guerra
Carlos Valverde López

Córdoba

Posadas

Montilla

Córdoba

Lucena

Cabra

Priego

Liberal-fusionista
Conservador-adicto
Republicano
Conservador-adicto
Liberal-fusionista
Gamacista
Conservador-adicto

Provincia de Málaga

Francisco Bergamín García Joaquín Chinchilla y Diez de Oñate

Campillos

Romerista

Coín

Liberal-fusionista

Velez Málaga

Conservador-adicto

Leopoldo Larios Sánchez

Marqués de Larios

Andrés Mellado Fernández

Francisco Romero Robledo

Joaquín Tenorio Vega

José Vignote Wünderlich

Málaga

Torrox

Málaga

Antequera

Ronda

Archidona

Conservador-adicto

Conservador-adicto

Liberal-fusionista

Romerista

Conservador-adicto

Conservador-adicto

\section{Provincia de Cádiz}

Ramón Auñón y Villalón

Bartolomé Bohorques Rubiales

Cádiz

Grazalema

Duque de Almodovar del Río

Jerez

Patricio Garvey y G.de Mota

Jerez

Federico Laviña Laviña

Marqués de Mochales

Pto.Sta.María

José M. Núñez de Reinoso

Antonio Ruiz Tagle y Lasanta

Jerez

Medina-Sidonia

Algeciras

Cádiz

Liberal-fusionista

Liberal-fusionista

Liberal-fusionista

Liberal-fusionista

Liberal-fusionista

Tetuanista

Conservador-adictó

Conservador-adicto

Conservador-adicto

\section{Provincia de Sevilla}

José Bores y Lledó

Hilario del Camino Martínez

Carlos De'gado Zuleta

Lorenzo Domínguez Pascual
Sanlúcar la $M$. Conservador-adicto

Sevilla

Utrera

Carmona
Gamacista

Conservador-adicto

Conservador-adicto 
Duque de T'Serclaes

Tomás de Ibarra González

Carlos de Iastra Romero

Marqués de Cuevas del Becerro

Marqués de Perales

Pedro Rdguez de la Borbolla

Anselmo Rodriguez de Rivas

Francisco Ruiz Martínez

Manuel Vázquez Rodríguez
Ecija

Sevilla

Marchena

Sevilla

Estepa

Sevilla

Cazalla

Sevilla

Morón
Conservador-adicto

Conservador-adicto

Conservador-adicto

Conservador-adicto

Conservador-adicto

Gamacista

Liberal-fusionista

Liberal-fusionista

Conservador-adicto

Provincia de Huelva

Manuel de Burgos y Mazo

Manuel García Iñiguez

José Limón Caballero

Francis J. Sánchez-Dalp
Ia Palma

Huelva

Valverde del $\mathrm{C}$.

Aracena
Conservador-adicto

Conservador-adicto

Liberal-fusionista

Conservador-adicto

\section{LAS CORTES DE LA LIQUIDACION}

Precedidas por el terremoto espiritual que ocasionó el desastre, dolientes aún por las amputaciones del territorio, y conmovidas por los movimientos de protesta, el día 2 de junio se abren las nuevas Cortes,con una misión casi en exclusivo de albacea:dar legalidad a la liquidación testamentaria de nuestra gloria imperialista. Pero su carácter fundamental no era por ello sólo político, sino económico y social, como se pone de relieve en el discurso de apertura de su presidente Alejandro Pidal,en el que hace una exaltación al sacrificio, que fue confirmado también en el mensaje de la Corona donde se interpelaba a la "liquidación", lo que lleva a los partidos de la oposición a plantear un plan de actuación consistente en *cerrar la bolsa*. Quizás, desde los debates parlamentarios sobre las leyes desamörtizadoras de Mendizábal que llegaron a popularizar la Hacienda, no se habían presenciado en las Cortes un clima tan persistente de fiebre económica (los 18 tomos del Diario de Sesiones agotan la atención del investigador ante la profusión de estados económicos de ordinaria administración y la enorme extensión de sus estadísticas). Hasta en los debates políticos y votos particulares que promueven la crisis del Gobierno se ofrecen preferentemente motivos económicos. Temperamentos perezosos a la investigación y a la estadística nos sorprenden en sus discursos con sus esfuerzos de estudio y documentación. A lo largo de las sesiones se advierte un noble afán de estímulo, una hidalga rivalidad por discutir enseñando o aprendiendo. Todo podría decirse de estas Cortes menos que fueron poco laboriosas.

"Economías y reorganización de servicios" era el único programa y plataforma política. El Gobierno y la mayoría parlamentaria guiaran el Presupuesto de la liquidación, por lo que sus líderes sin excepción 
emprenderían la conquista de la oposición interviniendo en las discusiones de presupuestos, discutiendo artículo por artículo, concepto por concepto y cifra por cifra; utilizan los votos particulares, los turnos en contra, las alusiones, las enmiendas, las proposiciones incidentales y demás medios reglamentarios. Hay presupuestos como el de Marina en el que intervienen veintitrés diputados y su resolución tarda en votarse cerca de un mes. Además, muchos de los parlamentarios que en legislaturas anteriores nunca o casi nunca abordaron otros temas que no fueran estrictamente políticos, ahora lo hacen desde los más áridos y difíciles asuntos técnico-económicos. Esta escrupulosidad parlamentaria incitaría simultáneamente a la intervención perseverante de los gamacistas y canalejistas, los cuales revisarían las inversiones a realizar capítulo por capítulo, movidos siempre por el lema cabalístico de *apretar los cordones de la bolsa*, y también de los republicanos, que combatirían tenazmente los desajustes presupuestarios. Sólo los grupos carlistas y romeristas tendrían fuerza para plantear, al hilo del examen de los presupuestos, debates de índole políticos. Todas y cada una de las intervenciones que generaron los diversos asuntos debatidos proyectan pasiones políticas inusitadas que, en ocasiones, alcanzan tonos de verdadera acritud, pero que en último extremo denotan una elocuencia regida por la intranquilidad y el malestar que originó la fiebre del desastre.

En efecto, en la sesión parlamentaria del día 17 de junio el Ministro de Hacienda Raimundo Fernández Villaverde presentó los presupuestos de la liquidación, ante la expectación de la Cámara y del país en gene$\mathrm{ral}^{31}$. Desde entonces, los presupuestos se constituirían en caballo de batalla del Gobierno y la mayoría parlamentaria con los distintos grupos de la oposición, sobre todo en lo referente a los proyectos de leyes complementarias que en ellos se insertaban (Impuesto de utilidades, derechos reales, minas, títulos y condecoraciones, cédulas personales, aduanas, exportación de minerales, transportes, azúcar, achicoria, consumos, viajeros y mercancías, timbre, gas y electricidad,sal y tabacos), pues al discutirlos se cuestionaba, no sólo la idea política y el proyecto económico del Gobierno, sino que también se luchaba por la mejora de las condiciones de vida colectiva e individual de cada ciudadano, toda vez que si llegaban a prosperar tal y como fueron presentados a la Cámara, era claro que se generaría una pérdida de confianza en el programa regeneracionista y en lá prosperidad económica de futuro ${ }^{32}$.

(31) Diario de Sesiones del Congreso, 17/VI/1899.

(32) JIMENEZ,J.A. La rebelión social granadina a los proyectos complementarios de tributación en los presupuestos de 1899. Congreso Conmemorativo del Centenario del Asalto Campesino a Jerez (1892-1992). Universidad de Cádiz, noviembre de 1992. 
También, junto a la tarea económica del Congreso, el Gobierno sometería a las Cámaras la segunda parte de su proyecto político, esto es, el ensayo de política intervencionista en favor de los débiles. Con esta su preocupación social, por medio de la aprobación del proyecto de Reformas Sociales, se inauguró una legislación social obrera donde se especificaban las bases de regulación de accidentes y jornada laboral de las mujeres y de los niños.En efecto, los proyectos de ley que el ministro de Gobernación propuso a las Cortes (.Ley de Accidentes del trabajo: y de -Reglamentación del trabajo de las mujeres y los niños") respondía al concepto dinámico de la cuestión social y tenían la virtualidad política de incorporar al programa conservador la tutela del intervencionismo estatal, que hasta ahora sólo se conformaba como patrimonio exclusivo del partido libera ${ }^{33}$. Sin duda alguna, los proyectos de Eduardo Dato, inspirados en un espíritu humanitario y progresivo, fueron la realización política más avanzada del Gabinete. En el debate intervinieron muy activamente Moret por el partido liberal y Azcárate por el republicano, amén de otros representantes parlamentarios, que lograron introducir modificaciones formales al texto originario; fueron contestados por el marqués del Vadillo (en nombre de la Comisión de Reformas), y por el propio ministro, como autor de ambos proyectos.

Fuera del Parlamento también subsiste un ambiente economicista; en las casas, en los cafés, en los teatros andaluces no se habla más que de hacer economías. Se poseía plena conciencia de ser una Nación venida a menos, de ahí la asunción de la fiebre vergonzante del ahorro misérrimo. Si días antes entre las autoridades andaluzas existía un estado de fiebre bélica y de prodigalidad económica arrogante, días después se pasó al recuento receloso de la mínima inversión, "se cuentan los garbanzos del rancho y los céntimos de gratificación al cornetín ${ }^{34}$.

Así a la embriaguez bélica sucedería la embriaguez económica, y a la autosuficiencia de lo español sucede una epilépsia de europeización. «Lo único que se debe admitir ya - se decía entre el pueblo andaluz- es lo europeo", por lo que se desata una campaña periodística y social contra el genuino saber español (se intenta cerrar Academias, Universidades, Ateneos y todo aquello que recuerda al Cid o a Cervantes), del que se hacen eco los partidos, como así se puede extraer de la lectura de la prensa andaluza y del Diario de Sesiones. El tratado de París, ratificado en estas Cortes, no es más que un adiós a la España triunfalista y el inicio de una conciencia nacional fundamentada en la reconstrucción y europeización del país.

(33) .El Defensor de Granada, del 26-7-1899.

(34) PALACIOS, L. op. cit, pg. 85 y ss. ABELLAN, J.L. op. cit. pg. 140 y ss. El Defensor de Granada, del 7 y 10 de junio de 1899. 